\title{
ORIGINAL ARTICLE \\ Frequency of Organophosphate Poisoning and its Outcome in SKBZ AK CMH Muzaffarabad
}

\author{
SIDRA ISHFAQ ${ }^{1}$, MUNAZZA NAZIR ${ }^{2}$, SAJID BUKHARI ${ }^{3}$, NAEEM AHMED ${ }^{4}$, MUHAMMAD FURQAN UBAID $^{5}$, HUMZA FAROOQ $^{6}$ \\ ${ }^{1}$ Postgraduate Trainee Medicine, SKBZ/AK, CMH Muzaffarabad, Azad Kashmir. \\ ${ }_{2}^{2}$ Associate Professor Medicine, AJKMC SKBZ/AK, CMH Muzaffarabad, Azad Kashmir. \\ ${ }^{3}$ Senior Registrar Medicine, AJKMC SKBZ/AK, CMH Muzaffarabad, Azad Kashmir. \\ ${ }^{4}$ Associate Professor Paediatrics, AJKMC, SKBZ/AK, CMH Muzaffarabad, Azad Kashmir. \\ ${ }^{5}$ Medical Officer, SKBZ/AK, CMH Muzaffarabad, Azad Kashmir \\ ${ }^{6}$ Postgraduate Trainee, SKBZ/AK, CMH Muzaffarabad, Azad Kashmir \\ Correspondence to Dr. Sajid Bukhari, Email: drsajidbukhari69@gmail.com Mob:0355-6268850
}

\begin{abstract}
Background: Organophosphate toxicity is a worldwide problem as this is equally easily available in rural and urban areas. Furthermore, the complications and outcome of the organophosphate poisoning was also examined.

Aim: to determine the frequency of organophosphate poisoning and its outcomes in this region with limited laboratory and ICU facilities.

Place and duration of study: SKBZ/AK CMH Muzaffarabad from January 2019 to December 2019.

Methodology: This observational, prospective analytical study was planned in Department of Medicine, SKBZ/AK CMH

Muzaffarabad. A total of 110 suspected poisoned patients were included having age between 12-60 years. Patients who had taken more than one poison were excluded from the study. The organophosphate poisoning was identified through pupil size, increased secretion and Glasgow Coma Scale.

Results: The average age of the patients was $24.38 \pm 6.35$ years. The male to female ratio was $1: 1.69$. Majority $77(70 \%)$ of the patients were single and resident in rural areas 59 (53.6\%). The incidence rate of organophosphate poisoning was 90 out of 110 $(81.81 \%)$. There were at least $75 \%$ cases of organophosphate poisoning among all poisoned cases with $p$ value 0.03 . The survival rate was $93.3 \%$ (84 out of 90 ). The most important factor affecting survival rate was the time lag between ingestion of the poison and initiation of specific therapy with $p$ value 0.022 .

Conclusion: Organophosphate poisoning has high incidence although has good prognosis and not a very problematic death rate. We also concluded that the survival rate can be improved through reduction in time lag before start the treatment.

Keywords: Cause of poisoning, Organophosphate poisoning, Complication of Organophosphate poisoning
\end{abstract}

\section{INTRODUCTION}

According to the estimates reported by the World Health organization (WHO) several million individuals are being poisoned per annum. ${ }^{1}$ Organophosphates are potent cholinesterase inhibitors capable of causing severe cholinergic toxicity following accidental or intentional ingestion of, or exposure to, agricultural pesticides. In Pakistan, organophosphate compounds (pesticides) are a significant cause of poisoning and increasing mortality from poisoning-related deaths. ${ }^{2}$ Most cases of acute poisoning are the result of self-poisoning with the intention of suicide. ${ }^{3}$ Additionally, majority of patients in acute poisoning are young (ageing between 19-28 years).

Acute OPP is a life threatening medical emergency and requires indoor management. ${ }^{4}$ In the absence of a known ingestion or exposure, the clinical features of cholinergic excess indicates the possibility of organophosphate poisoning. ${ }^{5}$ The management of these patients may be complex and protracted. ${ }^{6}$ All symptomatic patients should receive therapy with oxygen, atropine, an oxime (e.g. pralidoxime) and early respiratory support. ${ }^{7}$ The mortality in OP poisoning depends on various factors including early diagnosis, the time of the treatment, amount and type of the ingested substance, supportive management and timely respiratory support. ${ }^{8}$ Overall mortality due to self-poisoning is much higher in areas with limited medical services including laboratory facilities, ICU care and ventilator support ${ }^{1}$. Therefore, this study was conducted to determine the frequency of organophosphate poisoning and its outcomes in this region with limited laboratory and ICU facilities.

\section{PATIENTS AND METHODS}

After the approval of hospital ethical committee, the sample included the poisoned cases reporting in Emergency Department of SKBZ/AKCMH Muzaffarabad. The cases declared as poisoned

Received on 11-04-2021

Accepted on 19-08-2021 if they had a history of Organophosphorus compound poisoning (OPCP), compound ingestion as indicated by the patient or the relative, the transferring doctor or the signs and symptoms of cholinergic excess even in the absence of coherent history of poisoning. The sample size for this study was calculated through WHO calculator 1.1 keeping the proportion of OPCP 0.5 in poisoned cases, relative efficiency $10 \%$ and level of significance $5 \% 9$. The minimum samples required for this study was 97 so we include 110 patients. Informed consent was taken from all patients or from their attendants included in this study. Both male and female patients, having age between 12-60 years were included and patients who had taken more than one poison were excluded from the study.

Pupil size, Glasgow Comma Scale (GCS) and increased secretions was used for confirmation of OCP poisoning. In few cases having unclear presentation, atropine challenge $(0.6$ to $1 \mathrm{mg})$ IV was given and if increase in HR by more than $25 \mathrm{bpm}$ and flushing was noted for confirmation of poisoning. The clinical assessment was done during initial resuscitation indicated by the patient's condition to separate the OPCP patients from other poisoning patients. For further investigating, patients who were diagnosed as OPCP were categorized into three groups; mild having complain of nausea, vomiting, abdominal pain, hypersalivation, headache, dizziness and rhinorhea lacrimation; moderate having complain of anxiety, palpitation, drowsiness, irritability, muscle twisting, fasciculation, softness of voice small pupils and urine incontinence; severe having placid paralysis, incobrobenchial sec, difficulty in breathing or labored breathing, crac, rhonchi wheeze, respiratory failure, chempne and ards convulsion shock. The treatment protocol i.e. use of atropine, pralidoxime, early respiratory support, other supportive management and close monitoring until removal of muscarinic signs were adopted.

The prospective data was collected on self-designed proformas and was analyzed through SPSS-23. One sample t test was used to estimate the proportion of OPCP among all poisoned patients. Chi square test or likelihood ratio test was used to test the 
association of personal characteristics of the patients with severity of the poisoning. $P$ value less or equal to use as significant.

\section{RESULTS}

The average age of 110 patients was $24.38 \pm 6.35$ years. Out of them majority were female $69(62.7 \%)$, unmarried $77(70 \%)$, and resident of rural areas $59(53.6 \%)$. Out of 110 patients, majority 90 $(81.8 \%)$ were OPCP, $14(12.7 \%)$ sedatives and only $6(5.5 \%)$ were snake biting. Organophosphorus compound poisoning patients were identified through pupil size, secretions and GCS. Cross tabulation descriptive analysis of factors used to identify the type of poison patients is mentioned in Table 1. One sample one tailed $t$ test was used to estimate the minimum proportion of OPCP in overall poisoning cases in the concern population. The result showed that at least $75 \%$ cases were OPCP in poisoning cases with $p$ value 0.034 . The association of patient's personal characteristics with respect of specific OPCP is mentioned in Table 2.

Now out of 90 cases diagnosed at OPCP, 18(20\%) were have psychiatric history, majority $87(96.7 \%)$ were poisoned orally. The major intention behind the poisoning with OPCP was suicidal $84(93.3 \%)$, followed by accidental ingestion 3(3.3\%), field exposure $2(2.2 \%)$ and hospital exposure / environmental exposure $1(1.1 \%)$. In most of the cases, patients ingest the substance through pill $79(87.8 \%)$, powder $8(8.9 \%)$ and spray $3(3.3 \%)$.

Similarly, majority of the patients poisoned orally $87(96.7 \%)$ and only $3(3.3 \%)$ were poisoned through diffusion. The mean time of arrival to the hospital was $4.64 \pm 4.17$ hours. The minimum time of arrival was observed 1 hour and the maximum time was reported as long as 34 hours. Patients at the time of presentation were symptomatic having respiratory issues $50(55.6 \%)$, gastrointestinal toxicity $29(32.2 \%)$ and Central nervous system toxicity $11(12.2 \%)$. On the basis of the symptoms at present patients were categorized in mild $24(26.7 \%)$, moderate $38(42.2 \%)$ and severe $28(31.1 \%)$.

The average time needed for complete atropinization was $22.99 \pm 16.67$ hours. The minimum time needed for complete atropinazation was 1 hour whereas the maximum time was 49 hours. In first 24 hours after admission, majority patients 60 $(66.7 \%)$ had good prognosis while $30(33.3 \%)$ patients had poor prognosis. The patients who were admitted in ICU 30 (33.3\%) patients needed mechanical ventilation. After treatment, only 6 $(6.7 \%)$ patients were expired and we said that at most $12 \%$ patients were died with $p$ value 0.024 who were OPCP poisoned. The comparison of discharged and died cases with respect of lag time in hours to reach hospital is presented in Figure I.

Table 1: Descriptive analysis of qualitative variables used to identify the different poisoned patients.

\begin{tabular}{|l|l|c|c|c|}
\hline Identifiers & Categories & OPCP\% & Sedatives\% & Snake biting\% \\
\hline \multirow{3}{*}{ Pupil size } & Dilated & $9(0)$ & $4(66.6)$ & $10(71.4)$ \\
\cline { 2 - 5 } & Mid dilated & $71(92.2)$ & $2(33.4)$ & $4(5.2)$ \\
\cline { 2 - 5 } & Pin point & $19(7.8)$ & $0(0)$ & $0(0)$ \\
\hline \multirow{2}{*}{$\begin{array}{l}\text { Increased } \\
\text { secretions }\end{array}$} & Yes & $90(100)$ & $0(0)$ & $0(0)$ \\
\cline { 2 - 5 } & No & $0(0)$ & $6(100)$ & $14(100)$ \\
\hline \multirow{2}{*}{$\begin{array}{l}\text { Glasgow } \\
\text { coma scale }\end{array}$} & Mild & $51(56.7)$ & $5(83.3)$ & $8(57.1)$ \\
\cline { 2 - 5 } & Moderate & $34(37.8)$ & $1(16.7)$ & $6(42.9)$ \\
\cline { 2 - 5 } & Severe & $5(5.6)$ & $0(0)$ & $0(0)$ \\
\hline
\end{tabular}

Figure 1: Comparison of time lag between outcome of OPCP patients

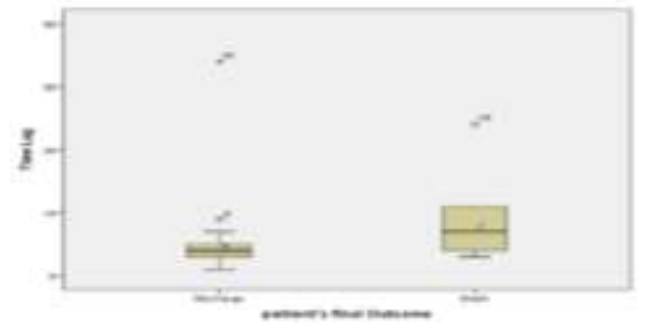

Table 2. Association of personal characteristics with respect of OPCP

\begin{tabular}{|l|l|c|c|c|}
\hline \multirow{2}{*}{ Gender } & Categorieries & OPCP & Others & P value \\
\cline { 2 - 5 } & Male & $34(82.9)$ & $7(17.1)$ & \multirow{2}{*}{0.82} \\
\cline { 2 - 4 } Marital status & Semale & $56(81.2)$ & $13(18.8)$ & \\
\cline { 2 - 4 } & Married & $63(81.8)$ & $14(18.2)$ & \multirow{2}{*}{1.00} \\
\hline \multirow{2}{*}{ Area } & Urban & $42(81.8)$ & $6(18.2)$ & \multirow{2}{*}{0.89} \\
\cline { 2 - 4 } & Rural & $48(81.4)$ & $11(17.6)$ & \\
\hline
\end{tabular}

\section{DISCUSSION}

The boxplot comparison showed that the average time lag of the "death cases" was higher 7 hours as compared to the "discharge cases" 4 hours. The box plot chart also showed the outliers of our data which are actually exceptional cases. Two outliers identified in patients who were finally discharge after treatment having time lag value 9 hours, identified as yellow card zone outlier and 34 hours identified as red card zone outlier. An outlier identified in patients with final outcome "death" having time lag value 24 hours with final outcome "death". Furthermore, the shape of the boxplot revealed that the distribution of "time lag" was not normal hence we used Mann-Whiteny U test to compare "time lag" between two groups of outcomes. The result showed that the mean rank of "discharge" patients was significantly low as compared to the patient who were died at end with $p$ value 0.022

Organophosphorus compounds have become increasingly popular for agricultural, industrial and home use and represent a significant potential health risk10. Due to its vast use, the organophosphorus is easily available in our concern area and that is the main reason that majority people suffered from Organophosphate poisoning either they chose themselves or accidently during work/visit was the major cause of mortality and morbidity.

In a recent study of 2020 conducted in Ethiopia, the incidence of OPCP was the most common poisoning agent 54 $(45 \%)$. They also reported that out of 120 poisoned cases, 66 $(55 \%)$ were female and $53(44.2 \%)$ were aged between $21-30$ years. 6 In an Indian study, the researchers showed that there were more male patients $59.89 \%$ in OPCP which was opposite to our study results. Poisoning cases were higher in rural areas $75.99 \%$ and the most common poisoning agent was OPCP $25.07 \%$ followed by snake biting $20.32 \% .{ }^{11}$ Similarly in another Indian study, the majority $40 \%$ of OPCP patients were aged between 21 30 years and the male to female ratio of OPCP poisoned patients was $4: 1^{12}$. In another study conducted in Karachi, the results were very similar results to our study. Out of 248 patients poisoned from OPCP agent, 181 (72.98\%) were female, having a mean age of $27.28 \pm 11.5$ years and $35(4.11 \%)$ patients were not survived. ${ }^{13}$

The mortality in OPCP poisoning depends on various factors including late diagnosis, delay in start of the treatment, amount and type of the ingested substance, supportive management and timely respiratory support10. Our study also showed the same results where average "time lag" was high in death cases as compared to the cases who were discharge after treatment. Like other factors, rout of poison in body was also very significant against survival. In a study conducted in 2018, the researchers divided the patients of OPCP into two groups i.e., non-oral rout poison patients and oral rout poison patients. The results showed that a high mortality rate was found in oral rout poison group ${ }^{14}$.

In a review from Pakistan, the researchers reviewed 623 articles. Out of 623 most of the studies are descriptive and case series in nature. Majority of the studies were planned only in urban areas. After a strict implementation of inclusion criteria, they included 110 articles. The results showed that in Pakistan mostly younger having age between less than 30 years of age were try for suicide with majority of male patients. ${ }^{15}$ The majority of poisoned cases were of male $64.5 \%$ having aged between $19-40$ years $(65.2 \%)$. Majority $77.5 \%$ of the patients were from rural areas and pesticides was the most common agent for poisoning $65.9 \%$. At the time of presentation, patient's condition was assessed through Glassgow Coma Sale and found that majority of the patients were 
mild $53.9 \%$ and minor symptoms $36.3 \%$. The overall mortality rate was observed $5.4 \% 3$. In our study, $64(58.18 \%)$ patients were mild, $41(37.27 \%)$ were moderate and $5(4.5 \%)$ were came in hospital with severe poisoning.

In an Indian study, the researchers discuss the difference of poisoning among male and females. They conclude that males were predominantly affected as compared to the female. Majority of the subjects were in between 30-40 years of age with the mean age of male was 40.5 years as compared to the female 34.4 years. The results showed that organophosphate was used by male subjects as compared to female who used zinc phosphide. ${ }^{16}$ In a European study the researchers trying to find the risk factors related with mortality in OPCP. They included 441 patients out which $69.16 \%$ were male. The survival rate was found $85.03 \%$. They concluded that the patient's age group greater or equal to 50 years, male and treatment pattern ATR, PAM and GPR are the significant risk factors having odds ratio $4.275,2.608$ and 2.233 respectively ${ }^{17}$.

In another study the researchers concluded that the mortality rate varies on the based-on amount of poison used, duration after exposure, and atropinisation of all the toxins. Case fatality from organophosphate poisoning varies according to the type of insecticide commonly used in the region ${ }^{8}$. In an Indian study, the researcher excluded the patients having double poisoning, concomitant illness and chronic lung disease. Out of 50 patients, $18(36 \%)$ were required ventilation and in $66 \%$ cases fasciculation was a noticeable feature. They used Glassgow Comma Scale score as predictor for prediction of ventilator support and concluded that a patient having GCS $\leq 10$ were required ventilation support ${ }^{18}$.

A retrospective study was conducted in Zagazig University Egypt and the results showed that mortality was associated with youth and with prolonged ventilated patients. They concluded that the mortality was relatively increased with lag time, amount of OP, pseudo cholinesterase levels and duration of ventilator support ${ }^{19}$. In another Indian study the researcher estimate the prevalence, clinical outcomes and the risk factors of OP poisoning. Out of 488 patients, $37.9 \%$ patients have complications, out of which aspiration Pneumonia developed in $13.9 \%$. The other complications were sepsis, acute renal injury, cardiac arrest, hypoxic ischemic encephalopathy (HIE) were associated with mortality ${ }^{20}$.

To avoid serious consequences patients who had coherent history of poisoning were closely monitored and admitted at least for a day, even if they were asymptomatic at presentation. In a recent study, the researchers concluded that in Pakistan ingestion of insecticides is considered in the top three ways of suicide and a public education campaign required to promote safe storage of insecticides ${ }^{21}$. This study was limited to the number of patients and did not cover the whole population of Azad Kashmir hence further detail study is required with large sample size and focused on other risk factors too. To find out the significant risk factors of the mortality a logistic regression analysis needs to be conducted on the same population to strengthen the findings.

\section{CONCLUSION}

Organophosphate poisoning is the commonest poisoning reported in the region. The death rate with organophosphate poisoning was not problematic and it will be more in control with reduction in time lag to start treatment.

\section{REFERENCES}

1. Pedersen B, Ssemugabo C, Nabankema V, Jors E. Characteristics of pesticide poisoning in rural and urban settings in Uganda. Environmental health insights. 2017;11:1-8.

2. Amir A, Raza A, Qureshi T, Mahesar GB et al. Organophosphate Poisoning: Demographics, Severity Scores and Outcomes From National Poisoning Control Centre, Karachi. Cureus.2020; 2(5): e8371.

3. Parashar A, Ramesh M. Assessment of the Sociodemographic Profile, Pattern, and Outcomes of Intentional Poisoning Cases in an Emergency Department of a Tertiary Care Teaching Hospital. Crisis. 2020; 41(6): 490-4.

4. Dong $\mathrm{H}$, Weng Y-B, Zhen G-S, Li F-J, Jin A-C, Liu J. Clinical emergency treatment of 68 critical patients with severe organophosphorus poisoning and prognosis analysis after rescue. Medicine. 2017; 96(25): e7237.

5. Shadnia S, Zamani N, Nikpour S, Saffaei A, Farnia MR. Atropine Challenge Test in Screening the Organophosphorus Poisoning Cases with Atypical Presentation; a Brief Report. Archives of academic emergency medicine. 2019; 7(1): e46.

6. Getie A, Belayneh YM. A retrospective study of acute poisoning cases and their management at emergency department of Dessie Referral Hospital, Northeast Ethiopia. Drug. Healthcare and patient safety. 2020; $12: 41-8$

7. Hulse EJ, Haslam JD, Emmett SR, Woolley T. Organophosphorus nerve agent poisoning: managing the poisoned patient. British journal of anaesthesia. 2019; 123(4):457-63.

8. Acikalin A, Dişel NR, Matyar S, Sebe A, Kekec Z, Gokel Y, et al. Prognostic factors determining morbidity and mortality in organophosphate poisoning. Pak J Med Sciences. 2017;33(3):534-9.

9. Yatendra S, Joshi SC, Singh M, Joshi A, Kumar J. Organophasphorus poisoning: An overview. Int J Health Sci Res. 2014; 4(8): 245-57.

10. Sujatha K, Thyagaraj V. A Clinical and Demographic Profile of Acute Poisoning in Adults: A Two Year Experience from a Tertiary Care Centre in Bangalore, India. J Advances in Medicine and Medical Research. 2017:1-10.

11. Ali I, Sawlani KK, Himanshu D, Chaudhary SC, Usman K et al. Study of pattern and outcome of acute poisoning cases at tertiary care hospital in north India. J Evid Based Med Healthc.2017;4(6): 2349.

12. Shareef ML, Kumar KR. A study profile and incidence of organophosphate poisoning at Gandhi hospital, Hyderabad, and Telangana-A three year study. Indian J Forensic and Community Medicine. 2019; 6(4):225-32.

13. Ahmed A, Ali L, Shehbaz L, Nasir S, Rizvi SRH, Zaeghum M, et al. Prevalence and characteristics of organophosphate poisoning at a tertiary care centre in Karachi. Pak J Surg. 2016; 32(4):269-73.

14. Jung WJ, Yu MH, Lee Y, Kim H, Cha YS, Park KH. Relative risk and clinical severity assessment in patients with non-oral route organophosphate poisoning compared with oral route poisoning. Yonsei Med J. 2018; 59(8):982-8.

15. Shekhani SS, Perveen S, Akbar K, Bachani S, Khan MM. Suicide and deliberate selfharm in Pakistan: a scoping review. BMC Psychiatry. 2018; 18(1):44.

16. Kanchan T, Menezes RG. Suicidal poisoning in Southern India: gender differences. J Forensic and Legal Medicine. 2008;15(1): 7-14.

17. Reddy BS, Skaria TG, Polepalli S, Vidyasagar $S$ et al. Factors associated with outcomes in organophosphate and carbamate poisoning: a retrospective study. Toxicolog Res. 2020; 36(3): 257-66.

18. Datla AV, Daddu R, Maske PGR. A prospective study on the predictors of mechanical ventilation in organophosphate poisoning. Int J Res Med Sci. 2020; 8(4): 1357-60.

19. Amin DM, Abaza MT, El Azawy DS, Ahmed Al. Morbidity and Mortality Indicators in Acute Organophosphate Poisoning in Zagazig University Hospital, Egypt: Retrospective Study. Occupational Diseases and Environmental Medicine. 2018;6(4):130-40.

20. Grace ST, Shrikar RB, Sri VRV, Mahesh SS, Rajendra PR, Vijayanarayana K, et al. Risk factors for the development of complications in Organophosphate and Carbamate poisoning. Research J Pharmacy and Technology. 2020; 13(1): 361-7.

21. Kerai SM. Trends and Predictors of Suicides in Pakistan. Pak J Med Res. 2017; 56(4):108-9. 